\title{
ÔRÍ E MEMÓRIA: O PENSAMENTO DE BEATRIZ NASCIMENTO
}

\author{
Rodrigo Ferreira dos Reis ${ }^{1}$
}

RESUMO: Este artigo tem como objetivo pensar os conceitos de Ôrí e Quilombo produzidos pela historiadora Beatriz Nascimento e suas interlocuções com os conceitos de memória e história. Para a produção deste estudo usamos como fonte os textos produzidos pela autora e publicados em diferentes jornais bem como sua obra oral “Ôrí”, apresentada no documentário produzido por Raquel Gerber. Primeiramente foi feita uma contextualização da vida e estudos de Beatriz Nascimento e sua ligação com os estudos pós-coloniais e, posteriormente, analisamos particularmente o conceito de Ôrí como possibilitador de uma memória coletiva ancorada no corpo negro e o quilombo como território corporal. Ôrí nos convoca como historiadores e acadêmicos a pensar o corpo, seus gestos, seus modos e sua linguagem como materialidade central para a produção de memória, de identidade e, portanto, de História.

Palavras-Chave: Memória; Corpo; Documentário Ôrí; Narrativas.

\section{INTRODUÇÃO}

Este artigo tem como propósito trazer a memória de Beatriz Nascimento através da análise de sua obra no que diz respeito ao conceito que ela nomeia como “Ôrí,”, bem como o que ele apresenta como a ideia de quilombo. Busca-se articular o pensamento da historiadora Beatriz Nascimento e apresentar sua narrativa para pensarmos tradição e oralidade como recursos de transmissão de conhecimento.

A justificativa para trabalhar com os textos e, principalmente, com a narrativa oral de Beatriz Nascimento se fez a partir do contato com a obra de Paul Ricoeur (2007) intitulada “A Memória, A História e o Esquecimento”. Nesse trabalho, o autor defende a ideia de que a memória pode ser um dever, ou seja, uma obrigação de lembrança. A memória, dessa forma, também é justiça, é um lembrar que se relaciona a uma ordem "lembrar para não repetir", relacionado a acontecimentos traumatizantes de nosso século, em especial à Shoah. O que o autor denomina "dever de memória” pode ser compreendido como um dever de fazer justiça à vítima, com a qual contraímos uma dívida

1 Mestrando em História, no Programa de Pós-graduação em História na Universidade do Estado de Santa Catarina UDESC. E-mail: rodrigodosreis76@gmail.com

Bolsista CAPES 
que temos obrigação de saldar. Nesse sentido, trazer os escritos de Beatriz Nascimento, para além de seu aporte teórico, também se relaciona com a ideia do autor de pensar um fazer justiça tanto ao esquecimento da autora como também mostrar o racismo (assim como o Shoah) como trauma nacional que nunca foi lembrado de forma propriamente justa, para que de fato possa ser esquecido, ou seja, como bem nos mostra Beatriz Nascimento e Paul Ricoeur ao usar a psicanálise de Freud para pensar a história: o Racismo brasileiro é um recalque que não para de se reatualizar (RICOEUR, 2007).

Ainda nesse interim, é preciso pensar as narrativas de sujeitos subalternizados desde uma perspectiva pós-colonial, tal como propõe Bhabha na obra “O local da Cultura” (2007), pois é através delas que os sujeitos, na discussão de suas próprias histórias, sustentam uma crítica ao eurocentrismo. Tais sujeitos, ao vivenciarem a experiência colonial e os processos brutais que ela impõe - a dominação, a desumanização, a perda de identidade, o preconceito racial, enfim o aviltamento próprio da experiência de colonização - se tornam, a partir de suas narrativas, portavozes legítimos do pós-colonial.

\begin{abstract}
toda uma gama de teorias críticas contemporâneas sugere que é com aqueles que sofreram o sentenciamento da história - subjugação, dominação, diáspora, deslocamento - que aprendemos nossas lições mais duradouras de vida e de pensamento. Há mesmo uma conviç̧ão crescente de que a experiência afetiva da marginalidade social - como ele emerge em formas culturais não - canônicas - transforma nossas estratégias críticas. Ela nos força a encarar o conceito de cultura exteriormente aos objets d'art ou para além da canonização da 'ideia' de estética, a lidar com a cultura como produção irregular e incompleta de sentido e valor, frequentemente composta de demandas e práticas incomensuráveis, produzidas no ato da sobrevivência social (BHABHA, 2007, p. 240)
\end{abstract}

Aqui, compreendemos que as narrativas textuais e orais traduzem-se enquanto atos de narrar, interpretar o tempo presente-passado, cujos sentidos e significados são constituídos na maneira como compartilham um saber de si e sobre si e, por meio deles, de modos específicos², constroem-se histórias. Assim, este trabalho pensa a história do tempo presente tal como propõe Rousso “a própria definição da história do tempo presente é ser a história de um passado que não está morto, de um passado que ainda se serve da palavra e da experiência de indivíduos vivos” (ROUSSO, 2007, p. 63).

Dessa forma, na perspectiva de um presente que se conecta com um passado através das narrativas de Beatriz Nascimento, escolhemos as citadas fontes para realização deste artigo. Tal escolha também se justifica através de diferentes estudos como os Beatriz Sarlo (2007) e Henry

2 Aqui é preciso ressaltar que há todo um debate teórico sobre as dificuldades e potências da História do Tempo Presente, contudo por questões de limites que são próprios de um projeto esta discussão será feita na dissertação. 
Rousso (2007) que apontam para o testemunho de autores silenciados pelas grandes narrativas históricas como fundamentais na construção de outras memórias. Assim, conceber as narrativas de sujeitos silenciados pelo "não lugar" em que Afro-Brasileiros foram colocados na história do ocidente pode apontar para uma forma de reorganizar esses sujeitos na produção de um saber sobre si, tal como propõe Sarlo: “A memória e os relatos de memória seriam a 'cura’ da alienação e da coisificação. Se já não é mais possível sustentar uma Verdade, florescem em seu lugar verdades subjetivas [...]. Não há Verdade, mas os sujeitos, paradoxalmente, se tornaram cognoscíveis” (SARLO, 2007, p. 46).

Beatriz Nascimento tem sua trajetória mais reconhecida no campo acadêmico entre 1968 e 1971, quando cursava História na Universidade Federal do Rio de Janeiro (UFRJ). No mesmo período, fez estágio em Pesquisa no Arquivo Nacional, com orientação do historiador José Honório Rodrigues. Posteriormente, tornou-se professora de História da rede estadual de ensino do Rio de Janeiro. Como pesquisadora procurou continuar sua carreira acadêmica em nível de pós-graduação na Universidade Federal Fluminense (UFF), sob orientação de Muniz Sodré (RATTS, 2006).

Há registros seus em entrevistas e jornais de circulação nacional (Suplemento Folhetim da Folha de São Paulo) e artigos publicados em periódicos relevantes: "Revista Cultura Vozes”, “Estudos Afro-Asiáticos” e “Revista do Patrimônio Histórico”. Beatriz Nascimento também compôs o Conselho Editorial do Boletim do Centenário da Abolição e República, no qual era responsável pelas entrevistas. Seu trabalho mais conhecido e de maior circulação consiste na autoria e narração dos textos do filme Ôrí (1989), dirigido pela socióloga e cineasta Raquel Gerber. Essa película documenta os movimentos negros brasileiros entre 1977 e 1988, passando pela relação entre Brasil e África, tendo o quilombo como ideia central. Beatriz Nascimento foi assassinada em 1995, levou cinco tiros de Antônio Jorge Amorim Viana que alegou que a historiadora, que lutava por igualdade entre homens e mulheres, interferiu em sua vida privada ao sugerir que a esposa dele se separasse por sofrer violência doméstica (RATTS, 2006).

Os temas principais de preocupação da autora eram: a) compreender o negro, sua história e identidade a partir de sua experiência diaspórica em um Brasil racista; b) o corpo como território entre os negros em condição de exílio de uma terra já que não mais existe e de impossível retorno; c) a linguagem ocidental como substrato fundamental para a compreensão da opressão e "prisão" existencial vivida pelos negros no Brasil, já que não daria conta das suas experiências visto que suas palavras foram construídas dentro de um contexto colonial de subalternização do negro (CID; REIS JUNIOR, 2012). 


\section{CONTEXTUALIZANDO O TRABALHO DE BEATRIZ NASCIMENTO DENTRO DO MOVIMENTO DE NEGRITUDE}

Beatriz do Nascimento foi inovadora ao apresentar África como um lugar imaginário e, ao mesmo tempo, concreto, de onde são construídas memórias e também de onde são produzidas histórias $^{3}$. A autora tem sido contextualizada como uma das precursoras dos estudos pós-coloniais, pois já apresentava uma noção de “perspectiva africana” dentro dos estudos sobre África e Diáspora, que segundo Barbosa (2012) se caracterizam principalmente por dois aspectos fundamentais: a) o continente africano, apesar de sua heterogeneidade e diversidade, deve ser entendido como uma totalidade - já que as divisões atuais partem das fronteiras produzidas pela expansão colonial europeia; e b) a África deve ser vista desde o seu interior, partindo do próprio continente como centro de interesse, considerando os africanos como sujeitos e não meros objetos da história (BARBOSA, 2012).

É comum dizer que o negro tem uma cultura própria. É claro que tem. E essa cultura é vinda de nossa origem africana. Então, tem-se o candomblé, umbanda e determinadas formas de comportamento, maneiras de se organizar, modos de habitar e uma série de outras coisas... Existe uma cultura realmente histórica e tradicional que seria a cultura de origem africana e uma outra cultura também histórica, mas que foi forjada nas relações entre brancos e negros, no Brasil. [...] o negro tem uma história tradicional onde subsistem ainda resíduos das sociedades africanas, mas tem, também, uma cultura forjada aqui dentro e que esta cultura, na medida em que foi forjada num processo de dominação, é perniciosa e bastante difícil e que mantém o grupo no lugar onde o poder dominante acha que deve estar. Isto é o que eu chamo de 'Cultura da Discriminação'. (NASCIMENTO, 1976, p. 04).

A citação introduz como Beatriz pensa a construção de identidade negra em diáspora enquanto permanência e transformação e, principalmente, aponta os fatores históricos das relações de poder dessas construções ao apontar a cultura de discriminação como própria dessa relação do negro no ocidente. Aqui, é importante contextualizar que, em relação aos africanos, os encontros com brancos europeus e seus descendentes, desde as interações mais iniciais, foram permeados por uma perspectiva eurocêntrica preconceituosa e colonizadora (KOSSOY; CARNEIRO, 1994).

Strother (1999) argumenta que houve um trabalho ativo e sistemático de produção de uma suposta identidade “tribal” africana caracterizada pelo descontrole, baixeza, bestialidade, preguiça,

3 Para Paul Ricouer, Memória e História são esferas distintas, mas irremediavelmente entrecruzadas, a começar porque compartilham um objeto comum: o passado. Desse modo, constituem-se em representações sobre o passado, mas o fazem por regimes diferentes (RICOEUR, 2007). 
agressividade, não-civilidade. Tais elementos foram utilizados de forma caricatural na construção de uma representação pejorativa dessas civilizações, representação que, de fato, se cristalizou no imaginário europeu no século XIX (STROTHER, 1999) e permaneceu no século XX com o racismo científico e, posteriormente, com o racismo estrutural. Assim, concordamos com Hall (1995) ${ }^{4}$ quando ele propõe que:

raça é um dos principais conceitos que organiza os grandes sistemas classificatórios da diferença que operam em sociedades humanas. E dizer que raça é uma categoria discursiva é reconhecer que todas as tentativas de fundamentar esse conceito na ciência, localizando as diferenças entre as raças no terreno da ciência biológica ou genética, se mostraram insustentáveis. Precisamos, portanto - diz-se - substituir a definição biológica de raça pela sócio-histórica (HALL, 2015, p. 01).

A relação entre brancos e negros sempre foi marcada por rupturas, descontinuidades, ressignificações, resistências, ou seja, mesmo que intensa e presente é marcada por tensões e não é homogênea, e pode ser caracterizada pelo que os estudos decoloniais tem nomeado como modernidade/colonialidade (QUIJANO, 1992). A argumentação principal apresentada por esses estudos nos volta à ideia de que a experiência da invasão e do processo de exploração e escravização das populações de origem africana e dos/as indígenas promovida neste continente ao longo de 500 anos construiu enunciados e práticas que classificaram, e ainda classificam, as populações do mundo por uma escala que identifica faltas e excessos em relação ao modo de vida europeu.

Esse olhar, produzido pela Europa e reproduzido no imaginário social brasileiro, apresenta a origem africana e também a África atual intimamente ligadas às ideias de escravidão; trabalho braçal; inferioridade intelectual; atraso tecnológico; falta de desenvolvimento cultural, moral, ético e estético (FANON, 2008). Nesse sentido, o eurocentrismo é também a base para o pensamento “intelectual” e produção do imaginário social brasileiro sobre o continente africano como o “Outro” da Europa. Aqui, é importante pensar o eurocentrismo tal como aponta Bernardino-Costa e Grosfoguel (2016, p. 18):

A partir do século XVI iniciou-se, portanto, a formação do eurocentrismo ou, como nomeia Coronil (1996), do ocidentalismo, entendido como o imaginário dominante do mundo moderno/colonial que permitiu legitimar a dominação e a exploração imperial. Com base

4 Uma conferência proferida por Stuart Hall em 1995 em Goldsmith College - University of London e reproduzida em documentário por Sut Jhally (C) Media Education Foundation, 1996. Está disponível na íntegra, em inglês, ilustrada por fotos e diagramas, no YouTube. Começa no minuto 6'40" da parte 2 do documentário "Race, the Floating Signifier”. Disponível em: <www.youtube.com/watch?v=SIC8RrSLzOs\&list=PL9DB8464B43CFAC14> e foi traduzido por Liv Sovik em: HALL, S. Raça, o significante flutuante. Tradução de Liv Sovik. Z Cultural, ano VIII, v. 2, 2015. Disponível em: <http://revistazcultural.pacc.ufrj.br/raca-o-significanteflutuante\%EF\%80\%AA/\#_edn4>. Acesso em: 21 jan. 2019. 
nesse imaginário, o outro (sem religião certa, sem escrita, sem história, sem desenvolvimento, sem democracia) foi visto como atrasado em relação à Europa. Sob esse outro é que se exerceu o "mito da modernidade" em que a civilização moderna se autodescreveu como a mais desenvolvida e superior e, por isso, com a obrigação moral de desenvolver os primitivos, a despeito da vontade daqueles que são nomeados como primitivos e atrasados (Dussel, 2005). Esse imaginário dominante esteve presente nos discursos coloniais e posteriormente na constituição das humanidades e das ciências sociais. Essas não somente descreveram um mundo, como o "inventaram" ao efetuarem as classificações moderno/coloniais. Ao lado desse sistema de classificações dos povos do mundo houve também um processo de dissimulação, esquecimento e silenciamento de outras formas de conhecimento que dinamizavam outros povos e sociedades.

É nesse tecido social que Achille Mbembe (2014) na obra “A Crítica da Razão Negra” argumenta que a categoria “Negro” produzida também na modernidade/colonialidade seria um exemplo total do "ser-outro", um símbolo de inferioridade que, de acordo com o ideal colonialista, devia ser ajudado e protegido. A África, da mesma forma, representaria um “não-lugar”, signo de atraso, de ausência de civilização e sem nenhuma contribuição à humanidade. Na visão eurocêntrica do colonizador, todas as contribuições africanas, sua obra e conhecimento, assim como a luta de seus povos na diáspora e sua contribuição para o desenvolvimento histórico das Américas, por exemplo, foram não só desconsideradas, mas absolutamente desconstruídas, ocultadas ou simplesmente apagadas.

Como apresenta Dussel (1993), a modernidade tem sua gênese numa relação dialética que o povo europeu estabeleceu com o não-europeu, o último, por sua vez, efeito dessa relação (a construção da ideia de “não-europeu”). A Europa só pode começar a construir uma narrativa sobre si na medida em que se deparou com o/a outro/a do descobrimento, controlando-o, violentando-o, dominando-o (DUSSEL, 1993). A modernidade, então, é conceituada a partir da violência, do genocídio dos povos encontrados na invasão das Américas. O genocídio é, inclusive, epistemológico, o que Sueli Carneiro chama de epistemicídio (CARNEIRO, 2005). Assim, a percepção moderno/colonial tem como ponto central e constituinte a definição de um ego descobridor, conquistador e colonizador da alteridade (DUSSEL, 1993; 2005). Aqui, é preciso apontar que um dos pilares do eurocentrismo e da colonialidade do poder tem sido as classificações raciais produzidas pelos homens da ciência em fins do século XIX ou como aponta Quijano:

Um dos eixos fundamentais desse padrão de poder é a classificação social da população mundial de acordo com a ideia de raça, uma construção mental que expressa a experiência básica da dominação colonial e que desde então permeia as dimensões mais importantes do poder mundial, incluindo sua racionalidade específica, o eurocentrismo. Esse eixo tem, portanto, origem e caráter colonial, mas provou ser mais duradouro e estável que o colonialismo em cuja matriz foi estabelecido. (QUIJANO, 2005, p. 117). 
Em resposta a esse processo de colonização, escravização e inferiorização dos africanos e, posteriormente, dos seus descendentes em diáspora que foram então nomeados como negros, surge em meados do século XX um movimento de ressignificação positiva das identidades raciais negras nomeado como negritude. Esse conceito aqui é entendido tal como propõe Munanga, ou seja, como fundamento da identidade negra, "a história comum que liga de uma maneira ou de outra todos os grupos humanos que o olhar do mundo ocidental 'branco' reuniu sob o nome de negros" (MUNANGA, 2009, p. 20). E neste texto, apresentamos Ôrí como a proposta de Beatriz do Nascimento de construção de negritude.

\section{3 ÔRÍ E QUILOMBO COMO CONSTRUÇÃO DE MEMÓRIA E IDENTIDADE}

Uma das obras fundamentais de Beatriz Nascimento foi o Filme "Ôrí”, trabalho que documenta os movimentos negros brasileiros entre 1977 e 1988, passando pela relação entre Brasil e África, além da própria história de vida e acadêmica da autora e que possui quilombo como ideia central para a compreensão do passado dos negros e projeto de futuro para uma resistência e permanência de culturas negras. O título do filme “Ôrí” tem sua origem na língua Yorubá, que significa “cabeça” ou “centro” e que é um ponto chave de ligação do ser humano com o mundo transcendental. Contudo, a autora propõe “Ôrí” como uma forma de produção identitária para os negros em diáspora uma relação entre intelecto e memória, entre cabeça e corpo, entre pessoa e terra. Para a autora, essa construção será capaz de retornar ao negro a dignidade e a humanidade roubadas e dilaceradas no processo de colonização, escravização e, posteriormente, de subalternização advinda do racismo.

Ôrí significa uma inserção a um novo estágio da vida, a uma nova vida, um novo encontro. Ele se estabelece enquanto rito e só por aqueles que sabem fazer com que uma cabeça se articule consigo mesma e se complete com o seu passado, com o seu presente, com o seu futuro, com a sua origem e com o seu momento...Então toda dinâmica desse nome mítico, oculto, que é o Ôrí, se projeta a partir das diferenças, do rompimento numa outra unidade. Na unidade primordial que é a cabeça, o núcleo. O rito de iniciação é um rito de passagem, de uma idade para outra, de um momento pra outro, de um saber pra outro, de um poder atuar para outro poder atuar (ÔRÍ, 1989, s.p.).

Segundo a autora, "Ôrí” contempla as dimensões temporais de passado, presente e futuro 
de uma forma não linear, o que só é possível porque o Ôrí se origina de uma memória que não é nem espontânea e nem forçada, mas, sim, ritualizada. Nas palavras da autora: "Existe uma linguagem do transe e a linguagem da memória, é neste momento que a matéria se distende e traz com muito mais intensidade a história, a memória, o desejo de não ter vivido em cativeiro[...]” (ÔRÍ, 1989, s.p.).

Nas reflexões de Beatriz Nascimento, Ôrí, dessa forma, propõe pensar a identidade individual e coletiva da população negra através de uma narrativa de encontro entre uma reconstrução da dignidade e o passado dos descendentes de escravizados, um projeto de humanização do negro e continuidade cultural para o futuro que produz uma identidade entre "eu e meus próximos” no momento presente. Dessa forma, podemos pensar que a proposta da autora, ao pensar a memória individual e a construção de identidade singular necessariamente ligada à memória de sua coletividade e identidade de grupo, vai ao encontro do pensamento de Paul Ricoeur, que propõe “uma constituição distinta, porém mútua e cruzada, da memória individual e da memória coletiva” (RICOEUR, 2007, p. 107). Um fator importante dessa construção de identidade proposta por Beatriz Nascimento é que de forma alguma ela acredita em um passado mítico e puro ou tampouco em um herói representativo de uma coletividade. A encarnação do “Ôrí” não é um regresso ao passado em África, já que para autora esta é uma terra que não mais representaria o sentimento de pertença, a história dos negros escravizados é a história de uma presença em terras de outros, portanto o corpo negro é o próprio território de pertença.

\footnotetext{
Não existem mais "bons selvagens" como não existem mais "negros puros” que saibam seu ramo africano no Brasil. Depois de nos explorar e tirar as melhores coisas, depois de nos reprimir, a ideologia dominante quer nos "descobrir" (como costumam dizer alguns dos paladinos em favor do negro) "puros", "ricos culturalmente", "conscientes de nossa raça”. Não entendem que esses ideais de pureza, beleza, virilidade, fortaleza que querem nos inculcar, são conceitos seus, impregnados de sua cultura; quanto à nossa consciência de nós só pode sair de nós mesmos e a partir de uma consciência do dominador. (NASCIMENTO, 1974 apud RATTS, 2006, p. 100).
}

Como propõe a autora, o corpo seria o grande guardião da memória e o indivíduo seria sujeito e objeto de si mesmo. Os corpos dos negros espelhariam entre si e os corpos se reconheceriam pelo contraste e pelo movimento ou deslocamento do corpo que carrega consigo um território abstrato, uma terra firme no “continente da memória”. A construção da imagem corporal no psiquismo também é a construção do Eu (que é comparado com a pele, isto é, a parte mais visível). Essa construção se dá tanto pela visão dos semelhantes quanto pela audição das histórias a 
respeito de si mesmo. São narrativas de um sujeito complexo que carrega consigo o quilombo e a senzala e seu corpo pode estar em movimento ou aprisionado, o seu "eu" pode estar ainda no cativeiro ou na liberdade da fuga. Para a autora, a fuga é uma outra categoria importante para entender "Ôrí” e “Quilombo” como conceitos, pois a fuga seria o próprio movimento do corpo colonizado, a fuga é o caminhar para liberdade e no caminho da fuga que se faz livre, não há ponto de partida e nem de chegada é o eterno caminhar da fuga que transformaria os sujeitos em condição de “cativeiro” real ou simbólico de estar colonizado em seres humanos.

A fuga passa a ser uma instituição decorrente desta fragilidade colonial e integrante da ordem do quilombo. O saque, as razzias, enfim o banditismo social, são a tônica que define a sobrevivência desses aglomerados (NASCIMENTO, 1985, p. 45).

Assim, a fuga também funciona como uma metáfora para os corpos negros e seria o verdadeiro devir para o homem negro, seria no movimento da fuga que ele encontraria o seu quilombo interno e o movimento que encontra com seus iguais e seus diferentes. Nesse movimento que a historiadora vê a permanência da memória dos quilombos para as favelas, das favelas para a cidade, da cidade para os postos de trabalho, para universidades e assim sucessivamente. (NASCIMENTO, 1985).

\section{O CORPO NEGRO COMO LUGAR DE MEMÓRIA: O CORPO COMO} QUILOMBO

Assim como a autora nos apresenta o Ôrí como possibilidade de totalidade para a construção identitária do negro em diáspora, ela também apresenta o quilombo como construção territorial que se apresenta metaforicamente como um eterno retorno ao território já não existente nem em África, nem no próprio território nacional.

É importante ver que, hoje, o quilombo traz pra gente não mais o território geográfico, mas o território a nível duma simbologia. Nós somos homens. Nós temos direitos ao território, à terra. Várias e várias e várias partes da minha história contam que eu tenho o direito ao espaço que ocupo na nação. E é isso que Palmares vem revelando nesse momento. Eu tenho a direito ao espaço que ocupo dentro desse sistema, dentro dessa nação, dentro desse nicho geográfico, dessa serra de Pernambuco. A Terra é o meu quilombo. Meu espaço é meu quilombo. Onde eu estou, eu estou. Quando eu estou, eu sou. (ÔRÍ, 1989, s.p.) 
[...] Gostaria de dar a este trabalho o título de "A memória ou a oralidade histórica como instrumento de coesão grupal”, ou ainda “A memória e a esperança de recuperação do poder usurpado". Esta maleabilidade de títulos possíveis talvez se deva ao fato de este não ser, ainda, um trabalho concluído. Trata-se de um estudo prolongado e exaustivo. (NASCIMENTO, 1982, p. 95).

As citações acima referem-se à escrita inicial de Beatriz Nascimento em seu texto “Kilombo e memória comunitária: um estudo de caso”, publicado originalmente em 1982 na revista “Estudos Afro-Asiáticos”, e nos apresenta, tanto no primeiro título, quanto no segundo, a mesma ideia que sua fala no filme "Ôrí: O quilombo como território simbólico ancorado no próprio corpo negro”. Nesse sentido, ela propõe como tese fundamental a ligação da memória com o território, ou seja, tal como Pierre Nora (1993), os quilombos, e principalmente Palmares, se apresentam como um "lugar de memória”.

Contudo, considerando um corpo usurpado, expropriado de seu território - tal como foram os corpos negros em diferentes processos que vão desde a escravização ao atual racismo estrutural faz sentido pensar a produção de memória coletiva ancorada no próprio corpo e é nisso que Beatriz e sua produção intelectual inovam, podendo, portanto, contribuir para ampliar a ideia de lugares de memória, pois, como ela mesma propõe, se não há mais o território, uma África que já não existe e uma terra que te mata, o que nos resta é o corpo e, portanto, o corpo é território, o corpo é quilombo. Ou seja, o corpo negro para Beatriz Nascimento é o próprio lugar de memória.

Para Pierre Nora (1993) "lugares de memória” são lugares materiais onde a memória social se ancora e pode ser apreendida pelos sentidos; são lugares funcionais, porque têm ou adquiriram a função de alicerçar memórias coletivas; e são lugares simbólicos nos quais essa memória coletiva vale dizer, essa identidade - se expressa e se revela. São, portanto, lugares carregados de uma vontade de memória. Nesse sentido, é possível, tal como propõe Beatriz Nascimento, pensar que a representação da própria materialidade negra - o corpo - tem atualmente cumprido a função de alicerçar as memórias afro-brasileiras de um passado comum, como é possível ver na reinvenção dos corpos negros através da positivação dos cabelos trançados, do black power, das vestimentas africanas. E, portanto, podemos dizer que, para além do corpo ser o próprio quilombo, ele é o lugar simbólico de construção de coesão grupal. O corpo negro é, por assim dizer, memória, é identidade, é território e resistência. Essa ideia também foi apresentada por Maria Antonieta Antonacci em seu livro “Memórias Ancoradas em Corpos Negros” (ANTONACCI, 2013) texto em que a autora elabora um método para a leitura daquilo que está inscrito não nos territórios geográficos ou nos textos escritos, mas daquilo que somente é possível ler quando se percebe: 
[...] memórias ancoradas em experiências dos que só têm no corpo e em suas formas de comunicação heranças de seus antepassados e marcas de suas histórias. Em contínuos desterros, sem construídas séries documentais, vivendo e transmitindo heranças em performances, recursos linguísticos e artísticos, povos africanos pluralizam nosso alcance de acervos históricos, monumentos e patrimônios audiovisuais, situando a necessária arqueologia de saberes orais, a ser enunciada e valorizada (ANTONACCI, 2013, p. 17).

O pensamento de Beatriz do Nascimento invoca em nós historiadores a necessidade de ampliar a linguagem para além daquela constituída sobre bases coloniais de dominação e de uma racionalidade que se propõe neutra e imparcial. Seu trabalho também nos remete a pensar como, através dessa nova perspectiva corpo/intelecto, cabeça e território são ordenados dentro de uma narrativa que comporte uma objetividade histórica. Em sua narrativa no documentário “Ôrí”, Beatriz do Nascimento faz menção a uma frase: "Eu sou atlântica” já dando uma noção de seu recorte temporal e espacial utilizados para compreender esta nova história do negro no Brasil.

Seguindo o seu entendimento, não há como falar de Brasil sem falar da África e até mesmo da América. Para ela, o movimento das grandes navegações foi o diálogo dos hemisférios Oriental e Ocidental do planeta. Esse empreendimento levou, de maneira forçada através do tráfico negreiro, a uma ligação de um território que se tornou um só: o Atlântico. Mas como esse processo passou por seu corpo e se configurou em um artigo "a” feminino dando um novo sentido para história do tráfico de seres humanos, que viviam em África. O “eu” seguido de um recorte geográfico mostra já a potência do corpo que sustenta um oceano e dois hemisférios. Seu corpo é um provável resultado do comércio de africanos deportados para as Américas. Esse retorno ao tema da escravidão em suas narrativas, tanto escrita como em comunicações orais, revelam como procedia as ligações de seus conceitos "humanizadores" para análise dos eventos que proporcionaram o grande movimento da história do encontro de civilizações. O "ganhar oceanos” ganhou outra proporção, ele se tornou o retentor de memórias dos povos que por ele navegou.

Assim, o retorno ao oceano é o momento crucial que autora determina seu recorte e observa as ressonâncias dos acontecimentos do século, as experiências trocadas das civilizações transatlânticas e apresenta sua visão do comércio escravagista, entendendo que não foram apenas os corpos dos africanos que foram comercializados, mas foi o que ele a determinar a troca do "soul”, a alma que jamais vai voltar.

Nesse momento, a autora expande nossa percepção sobre qual sua ideia de troca para além do comércio, o que mercadores africanos trocavam com mercadores europeus ou vendiam era muito mais do que corpos, eram almas. Assim, a experiência do atravessar o oceano não está só no corpo, está também na alma para a autora. 
Na medida em que havia um intercâmbio entre mercadores e africanos, chefes, mercadores também, havia uma relação escravo/escravo como também de intercâmbio, uma change. Essa troca era do nível do soul, da alma, do homem escravo. Ele troca com o outro a experiência do sofrer. A experiência da perda da imagem. A experiência do exílio. (ÔRÍ, 1989, s.p.).

Essa compreensão é o que permite pensar na ancestralidade um reconhecimento do próprio “eu” e da sua estrutura social. Trata-se de entidades que participam da vida real e espiritual dos indivíduos que aqui chegaram nas Américas coisificados mas que não se desligaram e, ademais, apesar da diversidade das formas e expressões assumidas, ainda é possível encontrar uma unidade que se estabelece em um passado comum. Ao pensarmos uma unidade na história africana somos remetidos, primeiramente, à ancestralidade, ao colonialismo, à descolonização e à religiosidade. Em segundo lugar, somos remetidos à diversidade e suas moléculas formadoras da cultura, como a linguagem, organização social e religiosidade - cosmovisão. Os movimentos de travessia, deslocamento e viagem se imbricaram corpo, despertando o eterno movimento da fuga e a volta para um lugar que não existe. Um território que só pode ser encontrado se o corpo se conectar com à alma, com o intelecto, enfim a própria ideia de "Ôrí”.

\section{CONSIDERAÇÕES FINAIS}

Ôrí nos convoca, como historiadores e acadêmicos, a pensar o corpo, seus gestos, seus modos e sua linguagem como materialidade central para a produção de memória, de identidade e, portanto, de História. Beatriz Nascimento questiona o saber que distingue corpo e mente, questiona nossa razão iluminista e recoloca no corpo o lugar central de resistência e existência. A autora, ao trazer já na década de 1990 um documentário que tem sua narrativa em primeira pessoa como trabalho central de sua obra, também apresenta outras formas de fazer história e coloca em si, na sua narrativa, a possibilidade de presentificar o passado vivido por ela, mas também por todo uma coletividade presente.

Ademais, é possível pensar que o Ôrí pode ser uma forma de reconhecimento de si, tal como propõe Saldanha (2009) ao trabalhar o conceito proposto por Ricouer. No reconhecimento de si, “o homem afirma-se e atesta-se como sujeito corpóreo, de carne e osso, capaz de se designar, de agir, de narrar a história da sua vida e de se apresentar e assumir como autor responsável pelos seus atos” (SALDANHA, 2009, s.p.). O acúmulo de memórias sobre Beatriz Nascimento na passagem do tempo se torna hoje uma força com um poder de cinesia, marcada por uma subjetividade de uma 
mulher negra que se questionava o quanto a representação do negro estava ligada a uma via de narrativa que desumanizava mulheres e homens tornando suas histórias de vida cheias de força vital em objetos pesquisa fixados no tempo e no espaço e relacionando suas experiências cotidianas a um vocabulário da escravidão.

Ôrí como conceito torna-se, então, uma ferramenta de alfabetização antidesumanização, um recurso da memória que o opera na completude do sujeito, um elemento agregador de subjetividade, um restaurador de tempo e espaço no qual o eu se manifesta em um instante e um local no que vai além da narrativa escrita da memória ritualizada, inscrevendo-se no corpo e solidificando o que se fragmentou na narrativa pessoal.

Na perspectiva de pensarmos Ôrí como fonte cultural com uma potencialidade de constituir no sujeito uma consciência de si, indubitavelmente recaímos sobre a estratégia da narrativa escrita. Ôrí, palavra com raízes na língua Yorubá, se articula diretamente com o conceito de quilombo também desenvolvido pela historiadora. A linguagem, por sua vez, é ligada à matriz $\mathrm{Mbudu}^{5}$ e se constitui como um vernáculo na diáspora, traduzindo sentimentos que antecedem a escravização. As palavras, ao tornarem-se conceitos abrem possibilidades no tempo e no espaço, redimensionando as representações do agenciamento na “figuração hibrida de espaço e tempo” (BHABHA, 2007, p.258) e, assim, as ações de corpos em fuga ganham novos significados na narrativa da historiadora .

Portanto, em suas narrativas, Beatriz Nascimento faz o reconhecimento desses corpos que falam de si e por si no tempo e no espaço, movimento que oferece chaves para o reconciliação desses mesmos corpos que foram coisificados em uma dada estrutura narrativa e o faz ao engendrar uma nova linguagem no diálogo entre quem escreve e quem lê. Beatriz Nascimento singulariza as ações dos sujeitos, provocando um novo imaginário sobre esses corpos e dimensionando outro caráter nos campos estético, religioso e político.

Assim as ações dos sujeito da história ressoam no tempo presente com outra pulsão de vida, ou seja, a música, o cinema, a religiosidade, a oralidade e outros aspectos culturais da diáspora africana pelo mundo se tornam elementos que possibilitam o ser e estar no tempo e no espaço. Os corpos, ademais, saem da condição de objetos e constituem uma nova identidade cultural para além da condição moderna que os subalternizou, viabilizando a criação de novos cenários que medeiem os corpos e as contrariedades das experiências cotidianas da vida real, formando uma base contestatória para as verdades históricas provisórias vigentes.

5 Em suas pesquisas para um novo conceito de quilombo Beatriz Nascimento identifica a palavra Quilombo sendo proveniente da matriz linguística Bantu com seu ramo Mbudu. 


\section{REFERÊNCIAS}

ANTONACCI, M. A. Memórias ancoradas em corpos negros. São Paulo: EDUC, 2013.

BARBOSA, M. S. A África por ela mesma: a perspectiva africana na História Geral da África (UNESCO). 2012. 222 f. Tese (Doutorado) - Faculdade de Filosofia, Letras e Ciências Humanas da Universidade de São Paulo. São Paulo, 2012.

BERNARDINO-COSTA, J.; GROSFOGUEL, R. Decolonialidade e perspectiva negra. Sociedade e Estado, Brasília, v. 31, n. 1, p. 15-24, Abr. 2016.

BHABHA, H. K. O local da Cultura. Belo Horizonte: Editora UFMG, 2007.

CARNEIRO, S. A construção do outro como não-ser como fundamento do ser. 2005. Tese (Doutorado) - Universidade de São Paulo, São Paulo, 2005.

CID, G. S. V.; REIS JUNIOR, P. H. Maria Beatriz Nascimento. Museu Afro Digital, 2012. Disponível em: <http://www.museuafrorio.uerj.br/?work=arquivos\%2C>. Acesso em: 25 jan. 2019.

DUSSEL, E. 1492: O Encobrimento do Outro - a origem do mito da modernidade. Petrópolis: Vozes, 1993.

DUSSEL, E. Europa, Modernidade, Eurocentrismo. In. LANDER, E. (Org.). A colonialidade do saber: eurocentrismo e ciências sociais perspectivas latino-americanas. Buenos Aires: CLACSO, 2005. p. 55-70.

FANON, F. Peles Negras, Máscaras Brancas. Salvador: EdUFBA, 2008.

HALL, S. Raça, o significante flutuante. Tradução de Liv Sovik. Z Cultural, ano VIII, v. 2, 2015. Disponível em: <http://revistazcultural.pacc.ufrj.br/raca-o-significante- flutuante\%EF \%80\%AA/\#_edn4>. Acesso em: 21 jan. 2019.

KOSSOY, B.; CARNEIRO, M. L. T. O Olhar Europeu: O Negro na Iconografia Brasileira do Século XIX. São Paulo: Edusp, 1994.

MBEMBE, A. Crítica da Razão Negra. Lisboa: Editora Antígona, 2014.

MUNANGA, K. Negritude: usos e sentidos. 3. Ed. Belo Horizonte: Editora Autêntica, 2009. 
NORA, Pierre. Entre memória e história: a problemática dos lugares. Projeto História. São Paulo, n. 10, p. 12. 1993.

NASCIMENTO, B. O negro visto por ele mesmo. Revista Manchete, Rio de Janeiro, p. 130131, set. 1976.

. Kilombo e memória comunitária: um estudo de caso. Revista Estudos AfroAsiáticos, Rio de Janeiro: CEAA/UCAM, v. 6-7, p. 259-265, 1982.

. O conceito de Quilombo e a resistência cultural negra. Afrodiáspora, ano 3, n. 6-7,

p. 41-48, $1985 . \quad$ Disponível em:

<https://edisciplinas.usp.br/pluginfile.php/4408010/mod_resource/content/2/NASCIME～NTO-

Beatriz_O\%20conceito\%20de\%20Quilombo\%20e\%20a\%20resist\%C3\%AAncia\%20cuＩturl \%20negra.pdf>. Acesso em: 21 jan. 2019.

ÔRÍ. Direção de Raquel Gerber. Brasil: Estelar Produções Cinematográficas e Culturais Ltda, 1989, vídeo (131 min), colorido. Relançado em 2009, em formato digital. Disponível em: <https:/www.facebook.com/uniaodetodasasnacoes/videos/1878768139068550/>. Acesso em: 20 jan. 2019.

QUIJANO, A. Colonialidad y modernidad/racionalidade. Perú Indígena, Lima, v. 13, n. 29, p. 11-20, 1992.

A colonialidade do saber: eurocentrismo e ciências sociais. Perspectivas latinoamericanas. Buenos Aires: CLACSO, Consejo Latinoamericano de Ciencias Sociales, 2005.

RATTS, A. Eu sou Atlântica: sobre a trajetória de vida de Beatriz Nascimento. São Paulo: Instituto Kuanza; Imprensa Oficial do Estado de São Paulo, 2006.

RICEUR, P. A memória, a história, o esquecimento. Campinas, SP: Editora Unicamp, 2007.

ROUSSO, H. A história do Tempo Presente, vinte anos depois. In: PORTO JR., G. (Org.). História do Tempo Presente. Bauru: EDUSC, 2007. p. 277-296.

SALDANHA, F. A. M. Do Sujeito capaz ao sujeito de direito: um percurso pela filosofia de Paul Ricoeur. 2009. Tese (Doutorado em Filosofia) - Universidade de Coimbra, Faculdade de Letras. Coimbra, 2009. 
SARLO, B. Tempo passado: Cultura da memória e guinada subjetiva. São Paulo: Companhia das Letras, 2007.

STROTHER, S. Z. Displays of the Body Hottentot. In: LINDFORS, B. (Ed.). Africans on Stage: Studies in Ethnological Show Business. Bloomington: Indiana University Press, 1999, p. 0161. 